\title{
Perbedaan Pengaruh Stretching Dengan Terapi Manipulasi Terhadap Peningkatan Aktivitas Fungsional Bahu Pada Penderita Frozen Shoulder
}

\author{
Futhri Rifa Zaimsyah \\ Program Studi D-III Fisioterapi Fakultas Kedokteran dan Ilmu Kesehatan Universitas Abdurrab \\ Jl. Riau Ujung no. 73 Pekanbaru \\ email : futhri.rifa@univrab.ac.id
}

\begin{abstract}
Background: Frozen shoulder or adhesive capsulitis is a diagnosis for all complaints of pain in limited motion of the shoulder joint. Complaints in the shoulder joint are usually preceded by trauma or immobilization which can result in joint stiffness. Frozen shoulder reduce functional activity of the shoulder and measured by SPADI questionnaire. Stretching and manipulation therapy are the the modalities that can be used by physiotherapists in dealing with impaired shoulder functional activity in patients with frozen shoulder. Research objectives: To determine the effect of stretching and manipulation therapy, to find out which one is better between stretching and manipulation therapy on shoulder functional activities in patients with frozen shoulder. Research Methods: Case study using two groups pre test - post test design divided into two groups, group I received stretching treatment while group II was treated with manipulation therapy, totally 16 subjects with frozen shoulder patients who were referred to the Physiotherapy Polyclinic of Rumah Sakit Umum Daerah Semarang. Results: Group I (stretching) the results of the different SPADI scores on the pre-post test obtained $p=0.012(p<0.05)$, while in group II (manipulation therapy) the results of the SPADI value difference test on the pre-post test were obtained results $p=0.012$ ( $p<0.05$ ), which means that there are a significant difference in stretching and manipulation therapy to increase shoulder functional activity in patients with frozen shoulder. In the Mann Whitney test, the results obtained were $p=0.001$ ( $p<0.05)$, which means that there were significant differences between the two treatment groups. Conclusion: Both stretching and manipulation therapy increase shoulder functional activity in frozen shoulder patients, but manipulation therapy is better than stretching in increasing shoulder functional activity in frozen shoulder patients.

Keywords: frozen shoulder, shoulder functional activity, stretching, manipulation therapy.
\end{abstract}

\begin{abstract}
ABSTRAK
Latar belakang: Frozen shoulder atau capsulitis adhesiva merupakan diagnosis untuk segala keluhan nyeri dalam keterbatasan gerak sendi bahu. Keluhan pada sendi bahu biasanya didahului oleh suatu trauma atau immobilisasi yang bisa mengakibatkan kekakuan sendi. Pada kasus frozen shoulder dapat mengganggu aktivitas fungsional bahu yang diukur dengan kuesioner SPADI. Stretching dan terapi manipulasi merupakan salah satu modalitas yang dapat digunakan oleh fisioterapis dalam mengatasi gangguan aktivitas fungsional bahu pada penderita frozen shoulder. Tujuan Penelitian: Untuk mengetahui pengaruh pemberian stretching dan terapi manipulasi, serta mengetahui mana yang lebih baik antara stretching dengan terapi manipulasi terhadap aktivitas fungsional bahu pada penderita frozen shoulder. Metode Penelitian: Case study dengan menggunakan two groups pre test - post test design dengan pembagian dua kelompok, kelompok I mendapat perlakuan stretching sedangkan kelompok II diberi perlakuan terapi manipulasi subjek penelitian berjumlah 16 pasien frozen shoulder yang dirujuk ke Poliklinik Fisioterapi RSUD Kota Semarang. Hasil : Pada kelompok I (stretching) hasil uji beda nilai SPADI pada pre-post test diperoleh hasil $\mathrm{p}=0,012(\mathrm{p}<0,05)$, sedangkan pada kelompok II (terapi manipulasi) hasil uji beda nilai SPADI pada pre-post test diperoleh hasil $\mathrm{p}=0,012(\mathrm{p}<$ 0,05), yang berarti terdapat perbedaan bermakna pada stretching dan terapi manipulasi terhadap peningkatan aktivitas fungsional bahu pada penderita frozen shoulder. Pada uji Mann Whitney diperoleh hasil $\mathrm{p}=0,001$ ( $\mathrm{p}<$ 0,05) yang berarti terdapat perbedaan yang bermakna antar kedua kelompok perlakuan. Kesimpulan : Stretching dan terapi manipulasi keduanya sama-sama meningkatkan aktifitas fungsional bahu pada penderita frozen shoulder, namun terapi manipulasi lebih baik dibandingkan stretching dalam meningkatkan aktivitas fungsional bahu pada penderita frozen shoulder.
\end{abstract}

Kata kunci : frozen shoulder, aktivitas fungsional bahu, stretching, terapi manipulasi. 


\section{Pendahuluan}

Frozen shoulder atau capsulitis adhesiva merupakan diagnosis untuk segala keluhan nyeri dalam keterbatasan gerak sendi bahu. Keluhan pada sendi bahu biasanya didahului oleh suatu trauma atau immobilisasi yang bisa mengakibatkan kekakuan sendi [1]. Frozen shoulder diklasifikasikan menjadi tipe primer dan tipe sekunder. Frozen shoulder primer bersifat idiopatik sedangkan frozen shoulder sekunder mencakup asosiasi dengan penyebab primer berupa trauma, rotator cuff tear, hemiparesis, penyakit kardiovaskular atau diabetes mellitus dll. Seperti definisi tesebut frozen shoulder idiopatik ditandai dengan spontan. Fibrosis pasif dari kapsul sendi bahu yang akhirnya menyebabkan kekakuan dan kecacatan [2].

Karakter dari Frozen shoulder ini yaitu adanya fibrosis, penurunan volume kapsul glenoid, nyeri yang progresif dan penurunan gerakan aktif dan pasif pada sendi bahu [3]. Nyeri pada Frozen shoulder sangatlah mengganggu, ini menjadi sangat berat dan mengganggu semua aktivitas sehari-hari dan mengganggu tidur malam hari karena individu dengan frozen shoulder sering terbangun karena rasa sakit pada bahu [4].

Insiden dari frozen shoulder pada populasi umum yaitu $2-5 \%$ dan $10-20 \%$ pada penderita diabetes. Penyakit yang tidak begitu jelas sebabnya ini terjadi pada sisi bahu yang lebih tidak dominan, prevalensi pada perempuan lebih tinggi dan lebih banyak terjadi pada individu usia 40-60 tahun [5].

Gejala frozen shoulder biasanya berlangsung lebih dari 6 bulan, paling lama 2 tahun, dan kemudian gejala perlahan-lahan berkurang [6]. Sayangnya ada beberapa kasus yang meninggalkan gejala permanen pada penurunan gerakan sendi [5]. Diagnosa frozen shoulder bisa dilihat dari berbagai karakteristik fisik seperti penebalan dari kapsul sinovial, adhesi dalam bursa subacromial atau bursa subdeltoid, perlengketan tendon biceps, dan obliterasi dari lipat axilla sekunder yang menjadi adhesi [7].

\section{Tinjauan Pustaka}

\subsection{Patofisiologi}

Pada frozen shoulder terdapat perubahan patologi pada kapsul artikularis glenohumeral yaitu perubahan pada kapsul sendi bagian anterior superior mengalami sinovitis, kontraktur ligamen coracohumeral, dan penebalan pada ligamen superior glenohumeral, pada kapsul sendi bagian anterior inferior mengalami penebalan pada ligamen inferior glenohumeral dan perlengketan pada ressesus akilaris, sedangkan pada kapsul sendi bagian posterior terjadi kontraktur, sehingga khas pada kasus ini rotasi internal paling bebas, abduksi terbatas dan rotasi eksternal paling terbatas atau biasa disebut pola kapsuler. Perubahan patologi tersebut merupakan respon terhadap rusaknya jaringan lokal berupa inflamasi pada membran sinovial dan kapsul sendi glenohumeral yang membuat formasi adhesive sehingga menyebabkan perlengketan pada kapsul sendi dan terjadi peningkatan viskositas cairan sinovial sendi glenohumeral dengan kapasitas volume hanya sebesar $5-10 \mathrm{ml}$, yang pada sendi normal bisa mencapai $20-30 \mathrm{ml}$, dan selanjutnya kapsul sendi glenohumeral menjadi mengkerut, pada pemeriksaan gerak pasif ditemukan keterbatasan gerak pola kapsular dan firm end feel.

Menurut Kisner (1996) [8] frozen shoulder dibagi dalam 3 tahapan, yaitu (1) pain (freezing), ditandai dengan adanya nyeri hebat bahkan saat istirahat, gerak sendi bahu menjadi terbatas selama 2-3 minggu dan masa akut ini berakhir ampai 10- 36 minggu, (2) stiffness (frozen), ditandai dengan rasa nyeri saat bergerak, kekakuan atau perlengketan yang nyata dan keterbatasan gerak dari glenohumeral yang di ikuti oleh keterbatasan gerak scapula. Fase ini berakhir 4-12 bulan, (3) recovery (thawing), pada fase ini tidak ditemukan adanya rasa nyeri dan 
tidak ada sinovitis tetapi terdapat keterbatasan gerak karena perlengketan yang nyata. Fase ini berakhir 6-24 bulan atau lebih.

\subsection{Metode dan Teknik Intervensi}

\subsubsection{Stretching}

Stretching adalah peregangan pasif maupun aktif yang ditujukan untuk otot-otot dan sendi. stretching adalah upaya untuk memperbaiki gerak dan fungsi dengan menggunakan latihan-latihan gerakan secara aktif atau pasif [8]. Pada kasus frozen shoulder stretching dapat membantu meningkatkan lingkup gerak sendi dan meningkatkan kekuatan otot sehingga dapat meningkatkan aktivitas fungsional bahu pada pasien. Streching pada sendi bahu juga dapat mencegah perlengketan yang terjadi pada kapsul sendi bahu. Dikatakan oleh Griggs et al, (2000) [9] bahwa sebagian besar kasus frozen shoulder idiopatik dapat diobati dengan peregangan pada bahu. Sambil menjaga gerakan bahu yang ada dan menambah gerakan pada akhir keterbatasan dapat meningkatkan gerakan pada sendi bahu.

Pada penelitian ini, stretching yang digunakan adalah self stretching yaitu pasien melakukan stretching secara mandiri sehingga pasien bisa memperkirakan seberapa nyeri yang bisa ditoleransi saat dilakukan stretching. Semua gerakan latihan yang dilakukan harus berada dalam kisaran sakit yang bisa ditoleransi oleh pasien dan menghindari memperburuk gejala dengan mendorong akhir ROM seperti gerakan lengan di atas kepala, menjadikan sisi lengan yang sakit sebagai bantalan kepala [11].

Gerakan yang dilakukan pada stretching ini yaitu sesuai pada keterbatasan gerak kearah pola kapsuler. Masing-masing gerakan dilakukan selama 8 kali hitungan dan 5-10 kali pengulangan pada setiap gerakan.

\section{a. Gerakan eksorotasi}

Posisi pasisi pasien tidur terlentang dengan lengan atas tersuport bed. Kemudian sambil memegang tongkat pasien diminta untuk menggerakkan lengan kesamping tanpa mengangkat lengan atas. Tahan hingga 8 hitungan dan ulangi sebanyak 5-10 kali.

\section{b. Gerakan Abduksi}

Gerakan ini dilakukan pada posisi pasien tidur terlentang, kemudian pasien diminta untuk mengangkat lengan dengan menggunakan lengan yang sehat. Tahan gerakan pada akhir LGS selama 8 hitungan kemudian kembali pada posisi awal dan ulangi sebanyak 5-10 kali.

\section{c. Gerakan Endorotasi}

Gerakan ini dilakukan pada posisi pasien berdiri. Kemudian pasien diminta untuk menarik tangan yang sakit kebelakang punggung dengan menggunakan sisi tangan yang sehat. Tahan gerakan pada keterbatasan LGS selama 8 hitungan, kemudian kembali pada posisi awal dan ulangi gerakan sebanyak 5-10 kali.

\subsubsection{Terapi Manipulasi}

Terapi manipulasi merupakan bagian dari mobilisasi sendi. Secara mekanis tujuannya adalah untuk memperbaiki joint play movement dan dengan demikian memperbaiki roll-gliding yang terjadi selama gerakan aktif. Terapi manipulasi harus diakhiri apabila sendi telah mencapai LGS maksimal tanpa nyeri dan pasien dapat melakukan gerakan aktif dengan normal.

Terapi manipulasi merupakan salah satu modalitas yang tepat untuk mengurangi nyeri dan memperbaiki disfungsi sendi karena terapi manipulasi dapat meregangkan jaringan lunak sekitar sendi yang memendek [11].

Terapi manipulasi yang dilakukan adalah traksi sendi bahu ke arah latero-ventrocranial, gliding caudal untuk perbaikan LGS ke arah abduksi, gliding posterolateral untuk perbaikan LGS ke arah endorotasi, gliding anteromedial untuk perbaikan LGS ke arah eksorotasi. 
a. Traksi sendi bahu ke arah latero- ventro cranial

Posisi pasien Pasien duduk, terapis berdiri pada sisi bahu yang sakit, kemudian tangan yang tidak sesisi memfikasi akromion menggunakaan ibu jari dan jari telunjuk. Tangan ynag lain memegang humerus dari medial, sedekat mungkin dengan sendi, kemudian melakukan gerakan traksi ke arah latero-ventro-cranial. Lengan bawah pasien rileks disangga lengan bawah terapis. Lengan bawah terapis yang berlainan sisi mengarahkan gerakan [11]. Traksi dipertahankan selama tujuh detik, diulangi sebanyak delapan kali.

\section{b. Gliding caput humeri ke arah caudal}

Gerakan ini untuk memperbaiki gerakan abduksi bahu. Posisi pasien tidur setengah miring setengah terlentang kesisi sehat, terapis berdiri di belakang pasien. Gelang bahu terfiksasi oleh posisi depresi. Tangan terapis sesisi memegang humerus sedekat mungkin dengan sendi dari lateral. Tangan yang lain diletakkan diatas tangan pertama. Kedua tangan melakukan gliding kearah caudal dengan bantuan berat badan [11]. Gerakan dipertahankan selama tujuh detik, diulangi sebanyak delapan kali.

c. Gliding caput humeri ke arah posterolateral

Pasien diposisikan tidur terlentang sedikit miring kesisi yang sakit, terapis berdiri di sisi bagian yang sakit. Skapula terfiksasi oleh tempat tidur. Tangan terapis diletakan pada lengan atas bagian ventral, sedekat mungkin dengan sendi dan selanjutnya melakukan gerakan gliding kearah posterior sedikit lateral. Lengan pasien disangga oleh tangan terapis yang lain [11]. Gerakan dipertahankan selama tujuh detik, diulangi sebanyak delapan kali.

\section{d. Gliding caput humeri ke arah antero - medial}

Posisi awal pasien tidur terlentang sedikit miring dan terapis berdiri di depan pasien.
Tangan homolateral memfiksasi akromion dari sebelah ventral dengan siku diletakkan diatas tempat tidur. Tangan yang lain diletakkan pada lengan atas dari sebelah dorsal dan sedikit mungkin dengan sendi, selanjutnya melakukan gerakan gliding ke arah anterior sedikit medial. Gerakan dipertahankan selama tujuh detik, diulangi sebanyak delapan kali.

\subsection{Pengukuran}

Alat ukur yang digunakan pada penelitian ini adalah SPADI (shoulder pain and diasbility index), yaitu bangko pengukuran untuk menilai nyeri dan kemampuan fungsional pada frozen shoulder. Total nilai dari pemeriksaan gangguan fungsional adalah bentuk rendah atau tingginya tingkat kesulitan saat melakukan aktivitas fungsional. Semakin tinggi nilai yang didapat maka semakin tinggi pula tingkat kesulitan pasien, begitu pila sebaliknya semakin rendah nilai yang didapat semakin mampu pasien melakukan aktivitas fungsional secara mandiri. Untuk menghitung nilai total adalah jumlah skor tiap jawaban pada kuesioner dibagi skor maksimum kuesioner dan dikalikan 100\%, sehingga total skor dinyatakan dalam persen.

Pada penelitian Clinimetric Evaluation of Shoulder Disability Questionnaires : a Systematic Review of The Literature, Didapatkan hasil bahwa SPADI tes memiliki validitas Cronbach's diatas $90 \%$ terutama untuk disability pada kasus frozen shoulder [12].

\section{Metode Penelitian}

\subsection{Rancangan Penelitian}

Jenis penelitian yang digunakan adalah perbandingan dua kelompok penelitian yang bersifat komparatif, yaitu kelompok I dengan pemberian stretching dan kelompok II dengan pemberian terapi manipulasi pada kondisi frozen shoulder.

\subsection{Tempat dan Waktu Penelitian}


Penelitian ini dilakukan di Pliklinik Fisioterapi RSUD kota Semarang. Pelaksanaan penelitian ini yaitu pada bulan Desember 2014 - Januari 2015.

\subsection{Subjek Penelitian}

Subjek pada penelitian ini adalah seluruh pasien frozen shoulder yang datang ke Poliklinik Fisioterapi RSUD Semarang pada 01 Desember - 27 Desember 2014 yang memenuhi kriteria. Kriteria dari penelitian ini yaitu (1) pasien frozen shoulder yang telah didiagnosis oleh dokter, (2) pasien bersedia menjadi subjek penelitian dengan mengisi informed consent, (3) pasien dengan usia $>20$ tahun, (4) nyeri dan keterbatasan luas gerak sendi pada gerakan pola kapsuler.

Kriteria eksklusi pada penelitian ini yaitu (1) pasien menderita diabetes melitus, (2) trauma atau kondisi bedah pada sendi bahu, (3) pasien mengalami kondisi rematoid arthritis. Sedangkan kriteria drop out pada penelitian ini yaitu (1) pasien tidak mengikuti terapi dua kali berturut-turut, (2) pasien tidak menyelesaikan prosedur penelitian, dan (3) subjek meminta untuk berhenti.

\subsection{Prosedur Intervensi}

Langkah-langkah yang diambil dalam prosedur penelitian ini dibagi menjadi dua bagian yaitu: tahap persiapan dan tahap pelaksanaan penelitian.

Pada tahap persiapan penelitian ini meliputi : (1) pengurusan izin penelitian pada pihak diklit dan Unit Instalasi Rehabilitasi Medis RSUD Kota Semarang sehubungan dengan pengambilan subyek penelitian, (2) pendekatan dengan pasien untuk dijadikan subyek penelitian dan untuk mendapatkan persetujuan dengan cara menandatangani formulir persetujuan sebagai subjek penelitian, (3) melakukan randomisasi yang dibagi dua kelompok secara acak dengan kelompok I mendapat perlakuan berupa stretching dan kelompok II mendapat perlakuan berupa terapi manipulasi.
Tahap pelaksanaan penelitian meliputi : (1) observasi awal dengan pengukuran aktivitas fungsional bahu, (2) melakukan program terapi selama bulan Desember 2014 sampai bulan Januari 2015 dengan frekuensi latihan satu minggu dua kali selama 5 minggu, (3) setelah 5 minggu melakukan terapi kemudian diobservasi kembali dengan pengukuran aktivitas fungsional bahu.

\section{Hasil dan Pembahasan}

\subsection{Hasil Penelitian}

Karakteristik berdasarkan jenis kelamin yaitu dari 16 subjek yang dibagi kedalam dua kelompok yaitu kelompok I (stretching) dan kelompok II (terapi manipulasi). Pada kedua kelompok terdapat 6 subjek laki-laki dengan prosentase $37,5 \%$ dan 10 subjek perempuan dengan prosentase $62,5 \%$. Kelompok I terdapat 2 subjek laki-laki dan 6 subjek perempuan. Sedangkan pada kelompok II terdapat 4 orang laki-laki dan 4 orang perempuan.

Analisis yang digunakan adalah nonparametrik. Menurut Hastono (2006) [13], prosedur jenis uji ditentukan oleh jumlah data yang diananalisis, bila jumlah data kecil $(<30)$ cenderung digunakan uji non parametrik. Dikarenakan subjek pada masing-masing kelompok < 30 maka peneliti menggunakan uji non parametrik.

\subsubsection{Uji beda sebelum dan sesudah perlakuan}

Perbedaan nilai SPADI pada kelompok I antara sebelum dan setelah terapi diketahui dengan Wilcoxon test dengan hasil nilai $\mathrm{p}=$ $0,012(\mathrm{p}<0,05)$, artinya ada perbedaan nilai SPADI antara sebelum dan setelah pemberian perlakuan pada kelompok I. Dari hasil diatas dapat disimpulkan perlakuan stretching berpengaruh dalam meningkatkan aktivitas fungsional bahu pada penderita frozen shoulder.

Sedangkan perbedaan nilai SPADI pada kelompok II antara sebelum dan setelah terapi 
diketahui dengan Wilcoxon test dengan hasil nilai $\mathrm{p}=0,012(\mathrm{p}<0,05)$, artinya ada perbedaan nilai SPADI antara sebelum dan setelah pemberian perlakuan pada kelompok II. Disimpulkan ada perbedaan terhadap peningkatan aktivitas fungsional bahu pada kelompok II.

\subsubsection{Uji beda kelompok I dan kelompok II sesudah terapi}

Perbedaan nilai SPADI antara kelompok I dan kelompok setelah terapi diketahui dengan Mann Whitney test dengan hasil nilai $\mathrm{p}=0,001$ $(\mathrm{p}<0,05)$, artinya ada perbedaan nilai SPADI antara kelompok I dan kelompok II sesudah perlakuan. Kesimpulannya ada perbedaan antara stretching dan terapi manipulasi setelah pemberian terapi dasar pada masing-masing kelompok.

\subsubsection{Perbandingan nilai rerata antara kelompok I dan II}

Untuk mengetahui kelompok mana yang lebih baik pengaruhnya dalam peningkatan aktivitas fungsional dilakukan ananalisis deskriptif dengan cara membandingkan selisih rerata sebelum dan sesudah perlakuan antara kelompok I dan kelompok II. Selisih rerata yang besar adalah perlakuan yang lebih baik. Diperoleh selisih sebelum dan setelah perlakuan pada kelompok I yaitu 2,44 dan selisih pada kelompok II sebelum dan setelah perlakuan yaitu 4,20. Terdapat perbedaan selisih antara kelompok I dan kelompok II, pada kelompok II diperoleh rerata yang lebih besar daripada rerata pada kelompok I yang berarti perlakuan pada kelompok II lebih baik daripada perlakuan pada kelompok I.

\begin{tabular}{|c|c|c|c|c|c|}
\hline & \multicolumn{2}{|c|}{ PRE DAN POST PERLAKUAN } & $\begin{array}{l}\text { NILAI S } \\
\text { AKUAN }\end{array}$ & & pada waktu stretching hanya beberapa $n$ \\
\hline SPADI & Pre Test & $\%$ & Post Test & $\%$ & nengganggu dari suplai oksi \\
\hline Kelompok I & 6,33 & $63,3 \%$ & 3,89 & $38,9 \%$ & metabolisme dari jaringan otot \\
\hline Kelompok II & 6,15 & $65,1 \%$ & 1,95 & $19,5 \%$ & $\begin{array}{l}\text { Dengan adanya perbaikan sirkulasi } \\
\text { 4,20 } \\
\text { rileksasi otot-otot penggerak bahu, maka }\end{array}$ \\
\hline & & & & & $\begin{array}{l}\text { berdampak pada penurunan nyeri } \\
\text { dirasakan penderita. Berkurangnya } \\
\text { memberikan keberanian pada penderita }\end{array}$ \\
\hline
\end{tabular}

\subsection{Pembahasan}

Sesuai dengan hasil olah data menggunakan bantuan program komputer diperoleh hasil stretching berpengaruh dalam meningkatkan aktivitas fungsional bahu pada penderita frozen shoulder.

Prinsip dari stretching adalah untuk merilekskan otot-otot sehingga peregangan dapat berpengaruh pada jaringan lunak tanpa gangguan otot. Jaringan bahu yang kaku tidak bisa ditarik secara tiba-tiba atau dengan kekuatan yang besar dengan demikian strategi inilah yang di terapkan, berupa peregangan lembut sehingga dapat meminimalisir nyeri [14] Selain itu serat kolagen yang terdapat pada ligamen yang tipis dengan serat elastis yang banyak, membuat ligamen lebih fleksibel daripada tendon [15] sehingga sendi akan lebih mudah untuk ditarik. Saat melakukan stretching harusnya tidak menimbulkan rasa nyeri atau juga memperberat nyeri, dilakukan dengan tarikan lembut, diberi sedikit penekanan dan kontraksi untuk merangsang aliran darah, rileksasi otot dan mencegah kontraksi statis.

Subtansi $\mathrm{P}$ yang menumpuk pada otot akan menimbulkan rasa nyeri. Tingginya tekanan intramuscular berhubungan dengan muscle tension dapat mengurangi sirkulasi pada otot. Aktivitas yang meningkat dari sistem saraf simpatik menyebabkan kontriksi dari pembuluh darah kecil arteriol dan demikian juga dapat mengurangi sirkulasi. Selama stretching akan benar-benar mengurangi kontriksi dari pembuluh darah sehingga menjadi lebih mudah saat tekanan intramuscular meningkat. Untuk sementara
efek dari stretching terhadap sirkulasi darah pada waktu stretching hanya beberapa menit

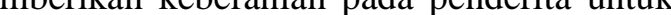


menggerakkan bahu saat melakukan aktivitas fungsional.

Pada teknik stretching pasien melakukan secara mandiri, sehingga pasien dapat merasakan toleransi nyeri yang ditimbulkan. Namun beberapa pasien dengan ambang nyeri yang rendah akan melakukan proteksi terhadap rasa nyeri yang dirasakan. Hal ini tentunya juga dapat mempengaruhi hasil terapi karena efek yang dihasilkan tergantung pada jumlah kekuatan dan durasi peregangan, pembuluh darah akan meregangkan jaringan ikat sekitarnya [15].

Terapi manipulasi juga dapat meningkatkan aktivitas fungsional bahu pada penderita frozen shoulder seperti yang diutarakan Morgan (2009) [5] yaitu tujuan dari terapi manipulasi ini adalah untuk secara meregangkan perlengketan yang membatasi gerak dan untuk mengembalikan gerak secara manual. Sehingga penderita mampu melakukan aktivitas tanpa adanya halangan karena keterbatasan gerak. Pemberian terapi manipulasi pada penderita frozen shoulder dengan kekakuan pola kapsuler dapat mencegah terjadinya degenerasi jaringan kolagen pada kapsul sendi, oleh karena dapat menstimulasi pembentukan glykosaminaglican dan memperlancar peredaran darah, selain itu juga dapat memisahkan perlengketan kapsul sendi bahu karena adanya jaringan fibrous [16].

Dengan terapi manipulasi yang artinya menggerakkan sendi bahu maka akan terbentuk kolagen baru terbentuk dalam kapsul tergantung pada gerak. Sebab tanpa adanya gerakan akan terjadi pengendapan yang abnormal antara serat kolagen baru dan serat kolagen yang sudah ada sebelumnya sehingga menghambat gerakan bahu [16]. Macam terapi manipulasi yang diberikan yaitu pada kekakuan pola kapsuler, dengan arah traksi kearah latero ventro kranial, slide kearah antero medial, slide ke posterior lateral dan slide ke kaudal yang masing-masing diberikan tarikan selama 6 detik yang diulang 7 sampai 10 kali dengan interval 3-4 detik setiap pemberian terapi manipulasi dapat menghancurkan pathology limitation yang disebabkan oleh adanya infiltrasi jaringan fibrous [8].

Beberapa hasil penelitian menunjukkan bahwa sebagian besar efek menguntungkan dapat dicapai dengan terapi manipulasi end range. Teknik manipulasi sering dibahas dalam pendekatan pengobatan klinis dan penelitian untuk kasus perlengketan kapsul dan kekakuan jaringan akibat frozen shoulder, teknik mobilisasi meregangkan kapsul dan meregangkan jaringan lunak sekitar bahu yang kaku [17]. Dengan terjadinya peregangan pada kapsul sendi, diharapkan adanya penambahan LGS bahu sehingga mengurangi keterbatasan aktivitas fungsional bahu.

Adanya perbedaan pada kedua kelomok perlakuan sudah dibuktikan melalui uji hipotesis yang menunjukkan adanya perbedaan antara kelompok stretching dan kelompok terapi manipulasi dalam meningkatkan aktivitas fungsional bahu pada penderita frozen shoulder dengan nilai $\mathrm{p}=0,001$. Dari perbandingan selisih rerata pada masingmasing kelompok diperoleh hasil rerata pada sebelum dan setelah perlakuan kelompok II (terapi manipulasi) lebih besar daripada kelompok I (stretching). Hal ini membuktikan terapi manipulasi lebih baik daripada stretching dalam meningkatkan aktivitas fungsional bahu pada penderita frozen shoulder.

\section{Kesimpulan}

Stretching dan terapi manipulasi keduanya sama-sama meningkatkan aktifitas fungsional bahu pada penderita frozen shoulder, namun terapi manipulasi lebih baik dibandingkan stretching dalam meningkatkan aktivitas fungsional bahu pada penderita frozen shoulder.

\section{REFERENSI}

[1]. Suharto, Suriani, \& Leksonowati, S.S, 2016. Pengaruh Teknik Hold Relax Terhadap Penambahan Jarak Gerak Abduksi Sendi Bahu Pada Frozen 
Shoulder Di Ratulangi Medical Centre Makassar. Buletin Penelitian Kesehatan, 44: 103-8.

[2]. Sah, S, Karn, S, et al. 2019. Effectiveness Of Intra-Articular Steroid Injection In Treatment Of Idiopathic Frozen Shoulder Followed By Physiotherapy And Home Exercise Program . Birat Journal of Health Sciences, 4(1): 611 - 615.

[3]. Gaspar PD., Willis FB., 2009; Adhesive capsulitis and dynamic splinting: a controlled, cohort study. BMC Musculoscelet Disord.

[4]. Mujianto, 2013; Cara Cepat Mengatasi 10 Besar Kasus Muskuloskeletal Dalam Praktik Fisioterapi; Jakarta.

[5]. Morgan, E. W., Managing the frozen shoulder; Diakses tanggal 20 Mei 2014, dari http://www.medicalnewstoday.com/articl es/166186.php

[6]. Vermeulen H. M., et al., 2000; End range mobilization tecniques in adhesive capsulitis of the shoulder joint: A Multiple Subject case report. Phys Ther. 2000.

[7]. Manske RC, Prohaska D,.2008; Diagnosis and management of adhesive capsulitis. Curr Rev Musculoskelet Med

[8]. Kisner, Carollyn dan Lyn Allen Colby, 1996; Threpeutic Exercise Foundation and Tecnique, Third Edition, DA David Company, Philadelphia.

[9]. Griggs, S. M. M.D., Anthony ahn, M.D., AND Green, A. M.D., 2000; Idiopathic Adhesive Capsulitis; The Journal of Bone and Joint Surgery, Incorporated

[10]. Leonard, F., 2007; Frozen Shoulder. Diakses pada 12 September 2014 www.shoulderdoc.co.uk

[11]. Syatibi, M., 2002; Terapi Manipulasi Ekstremitas; Pelatihan Manual Terapi, Solo.

[12]. Bot, S.D.M., Terwee., Windt, V.D., et al., 2003; Clinimetric Evaluation of Shoulder Disability Questionnaires : a Systematic Review of The Literature, Amsterdam.

[13]. Hastono., 2006; Statistik Kesehatan. Jakarta: Rajagrafindo Persada
[14]. UW Medicine, 2014 "Home Exercises for the Stiff Shoulder" http://www.orthop.washington.edu/ diakses pada 8 April 2015

[15]. Ylinen, J., 2002; stretchinh therapy for sport and manual therapies. Finland

[16]. Donatelli, R.A., 1991; Physical therapy of the shoulder, Churchill Livingstone Inc, New York.

[17]. Yang, J., Chang, C., 2007; Mobilization Techniques in Subjects With Frozen Syndrome; Journal of American Physical Therapy Association.

\section{Nama Penulis}

1. Futhri Rifa Zaimsyah, memperoleh Sarjana Sains Terapan Fisioterapi pada tahun 2015 di Poltekkes Kemenkes Surakarta. Kemudian tahun 2018 telah menyelesaikan Master Fisioterapi di KPJ Healthcare Uiversity College. Saat ini sebagai Dosen Tetap Prodi D-III Fisioterapi Universitas Abdurrab. 